\title{
Apertural characteristics of certain unilocular foraminifera: methods of study, nomenclature and taxonomic significance
}

\author{
ROBERT KNIGHT \\ The Laboratory, 18 Western College Road, Plymouth, Devon PL4 7AG, UK
}

\begin{abstract}
A method is described for cracking open the tests of foraminifera in order to examine in detail the structure of the apertural apparatus; it is used in the examination of certain unilocular forms included in the Nodosariida and the Buliminida. Four distinct types of aperture are described in species which have at some time been included in the genus Oolina. Four new terms, 'endosolen', 'exosolen', 'endoanulus' and 'endodisc' are formally proposed to describe structures related to the apertural apparatus in these and other species. The need is indicated for a further revision of the taxonomy of the unilocular Nodosariida and Buliminida which should follow a re-examination of certain holotypes.
\end{abstract}

\section{INTRODUCTION}

A major revision of the classification of the unilocular Nodosariida and Buliminida (foraminifera) was carried out by Jones (1984) who used taxonomic criteria such as would have been used in the case of multilocular forms but which had not previously been consistently and precisely applied to unilocular tests. This classification was a significant advance on previous work in which the unilocular forms had been grouped together simply because they were unilocular; however, it relied on earlier descriptions of types with regard to taxonomic criteria, such as the presence or absence of an internal tube.

Earlier workers had themselves relied on the transparency of the test in some species and on fortuitously broken tests in others for knowledge of internal tubes and other aspects of the apertural apparatus, but information derived in this way was not always adequate. A particular difficulty is apparent in the case of species included in the genus Oolina d'Orbigny, 1839. This genus was erected for 'O.' laevigata d'Orbigny, 1839 but no mention was made of the presence of an internal tube in the original description. Subsequent authors," however, considered that it did have a tube. Moreover, precisely what constitutes a tube has not been properly defined. Thus Poignant (1984), in line with previous authors, considers that the rim present inside the test of 'O.' williamsoni (Alcock, 1865) is an internal tube, albeit a small one; but this view is at least debatable.

Because the correct generic placement of a great many 'lagenoid' species is dependent on a precise knowledge of their structure, in particular that of their holotypes, there is now a need for a new systematic examination of the apertural characteristics, both internal and external, of the unilocular foraminifera in order to amplify the revision of Jones (1984). The first stages of such a study are presented here. The second stage, in which any necessary revisions of generic diagnoses will be made, will follow after a re-examination of relevant holotypes. Until that time it is preferable, when referring to Oolina auct., to place the name in inverted commas.

\section{MATERIALS AND METHODS}

\section{Source of material}

Foraminifera used in this study were collected from the Recent deposits in Pegwell Bay, Kent, England. Samples of sand and mud were taken from seven sites between high and low water and from depths up to $1.7 \mathrm{~m}$ into the sand on a transect about $1 \mathrm{~km}$ long and running approximately in a southeasterly/northwesterly direction with Ordnance Survey reference TR350634 as its midpoint.

The material was wet-sieved and four fractions between $660 \mu \mathrm{m}$ and $90 \mu \mathrm{m}$ were collected and dried. Foraminifera were floated on tetrachloromethane ( = carbon tetrachloride) and all the unilocular tests hand picked.

\section{Methods for studying internal structures}

Internal structures were revealed by cracking the tests in various planes. This was done using sewing machine needle which had been ground and polished either to a point or to a sharp curved blade. The size of the point was quite important as too fine a point led to neat holes being drilled in the test which did not then crack in two (Pl. 1, fig. 1; Pl. 2, fig. 1). The prepared needle was mounted in a pin vice. The chosen test was transferred with a drop of water by brush into a small rectangular well cut in the surface of a piece of X-ray film. As the water was slowly absorbed into the 
emulsion of the film the test was manipulated by the needle so that it became jammed into a corner of the well and held there by the needle; a slight additional pressure was enough to crack the test. It was essential that water remained in the well and that the test remained wet during the cracking process or the two halves of the cracked test would fly apart and be lost or damaged. By carefully positioning the test relative to the cutting edge, it was frequently possible to crack the test longitudinally through the aperture. In order to avoid damage to internal structures, extreme care was necessary in separating the two halves of a cracked test which tended to hold together by capillary attraction.

The external tube (called the exosolen hereafter), when present, readily broke away from the parent test unless care was taken not to subject it to untoward pressure from the needle or the sides of the well.

Pieces of foraminiferal test obtained in this way were mounted with a drop of water on negative film glued to a stub and examined in a Jeol T20 Scanning Electron Microscope.

Over 150 scanning electron micrographs were made, some of which were of the cracked tests of 10 or more animals.

\section{Numbers of specimens}

In all, several hundred specimens were examined, and not less than 50 of each species or species group reported on here were cracked for an examination of their internal structures.

\section{Diagrams}

The diagrams (Figs. 1-4) have been made after an examination and interpretation of whole and opened tests and scanning electron micrographs of them. They represent structural features which were constant and which could be used unequivocally to differentiate between species or species groups.

\section{RESULTS}

\section{Nomenclature}

Williamson's (1848) adoption of Ehrenberg's word 'Entosolenia' for the name of a genus led to the use of the word, in its adjectival form, not to describe a test or an animal, as in the expression 'an entosolenian foraminifer' (that is a foraminifer with an internal tube) but to describe the tube itself. There arose, therefore,

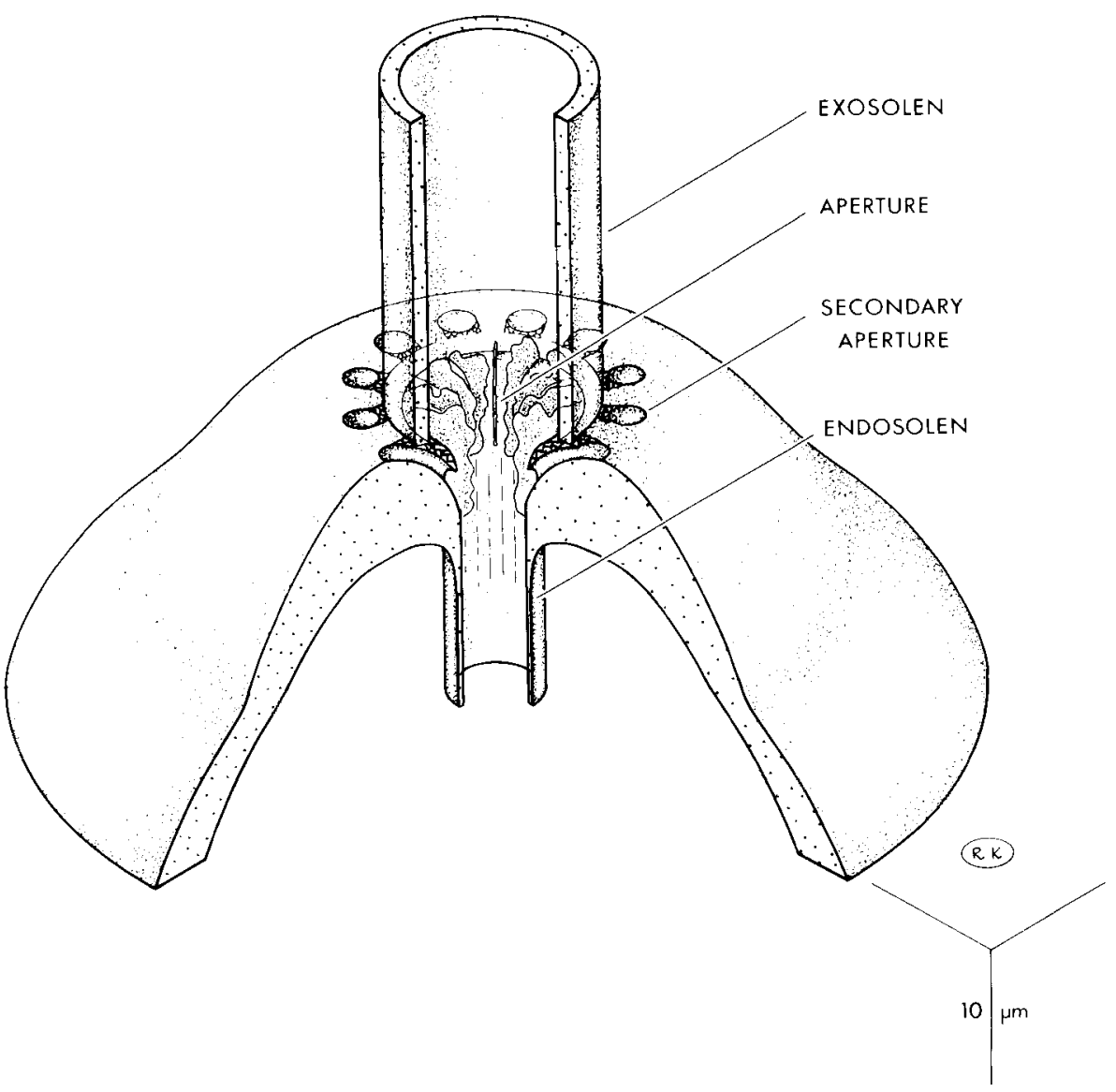

Fig. 1. 'Oolina' lineata (Williamson). Diagrammatic isometric projection of the apertural end of the test; both the endosolen and the exosolen have been truncated. 


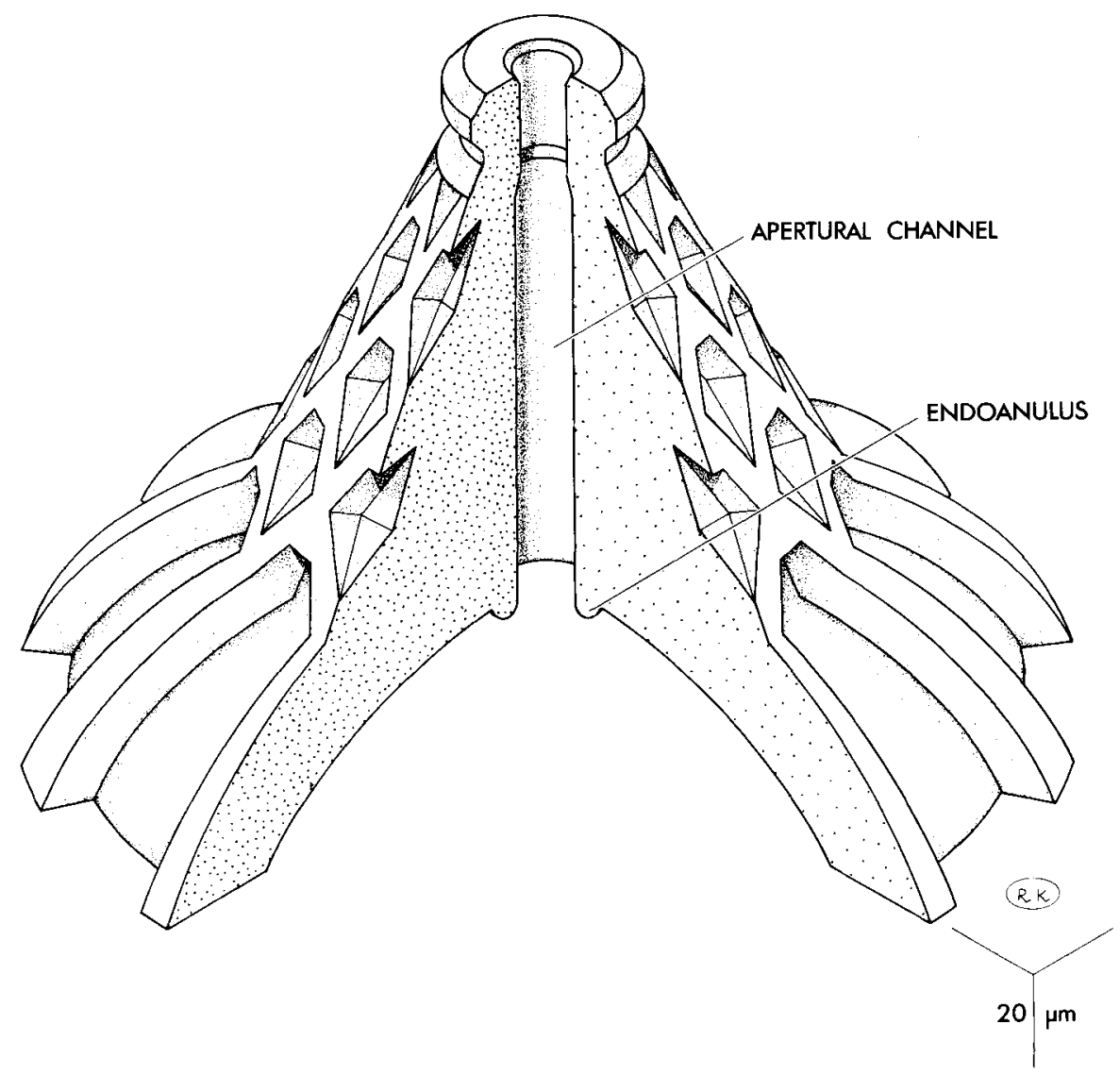

Fig. 2. 'Oolina' williamsoni (Alcock). Diagrammatic isometric projection of the apertural end of the test.

the very common yet tautologous expression 'entosolenian tube', that is a tube such as is present in the genus Entosolenia, and this in spite of the fact that no other kind of tube had been described in unilocular species. Other authors have used the double tautology 'internal entosolenian tube'.

Williamson had erected Entosolenia to separate tests with a tube projecting internally from those with an external tube or neck, for which he retained the generic designation Lagena Walker \& Jacob, 1798. He regarded the internal tube as "a very similar tube, only occupying a reversed position" to the external tube or neck. The term 'el, osolenian tube' then led to the equally tautologous expression 'ectosolenian tube' (in the absence of the ge:rus Ectosolenia), but this phrase fails not only by virtue of the tautology but also because by implication an ectcsolenian tube is in some way related, as Williamson (1848) clearly thought, to an entosolenian tube, but on the outside of a test rather than on the inside. As applied to the neck of Lagena, as it frequently has been, the term is misleading because the elongated neck of members of this genus is seen by scanning electron microscopy to be no more than a smooth, narrowing continuation of the bulbous part of the test (Pl. 1, fig. 11). Examination by transmitted light (especially when a test partly filled with water is drying out) confirms that there is no tube distinct from the rest of the test as there is in the case of both the internal and external tubes of other genera.

However, the term 'ectosolenian tube' (Parr, 1947) has also been used to describe a tube which is external to the test in some species of Oolina as presently understood. Thus the term 'ectosolenian', having been applied to two quite unrelated structures, is ambiguous and therefore imprecise.

The work reported in this paper is concerned with the apertures of unilocular foraminifera and with structures both internal and external to them. In order to avoid the imprecision and tautologies associated with the adjectival phrases, 'entosolenian tube' and 'ectosolenian tube', the words 'endosolen' and 'exosolen' are formally introduced to replace them. The terms 'endoanulus' and 'endodisc' are likewise formally proposed for two other structures which lie inside the test of certain species, both to differentiate between them and to avoid their possible confusion with internal tubes.

Endosolen. Pl. 1, figs. 1-3, 5-10; Figs. 1, 3. The internal tube present in, for example, Fissurina, Parafissurina, 


\section{Explanation of Plate 1}

The vertical edge of each photograph acts as a scale bar and its scale length is denoted in the caption as $\mathrm{V}$. Figs. 1-6. 'Oolina' lineata (Williamson).

Fig. 1. Both endosolen and exosolen may be seen in this specimen from which the basal half of the test has been removed. The holes near to and at the broken edge were made during unsuccessful attempts to crack the test in half. This was eventually accomplished using a needle which was at once less sharp and less polished. $\mathrm{V}=$ $285 \mu \mathrm{m}$.

Fig. 2. The upper part of a test which has been cracked through the aperture so as to reveal the internal structure of both the endosolen and the exosolen. The distal part of the endosolen was broken off during cracking. $\mathrm{V}=$ $70 \mu \mathrm{m}$.

Fig. 3. The manner in which the base of the exosolen rests on the radial laminae of the apertural channel is shown in this section through the aperture. $\mathrm{V}=65 \mu \mathrm{m}$.

Fig. 4. The exosolen is surrounded by supplementary apertures which are partially occluded. $\mathrm{V}=80 \mu \mathrm{m}$.

Fig. 5. The exosolen is mostly missing and is represented by a ring which separates the primary aperture from the supplementary apertures. Had the base of the exosolen not been present, the primary aperture would be seen as surrounded by grooves rather than secondary apertures. $\mathrm{V}=50 \mu \mathrm{m}$.

Fig. 6 . The test has been cracked through the aperture to show the inside of the exosolen and the apertural channel. The endosolen is commonly seen to be directed towards the abapertural apparatus even when, as in this specimen, this does not like on the major axis of the test. The plane of the free end of the endosolen is frequently seen to be roughly parallel to the plane of the abapertural apparatus in these circumstances. $\mathrm{V}=$ $220 \mu \mathrm{m}$.

Figs. 7, 8. ?'Oolina' lineata (Williamson).

Fig. 7. Detail of fig. 8. Coaxial tubes form the endosolen in this specimen which, from outward appearances, conforms to ' $O$.' lineata. Only one example of this form has been identified and it is not known, therefore, whether it is a freak, whether it represents a new taxon, or whether it is a stage in the normal development of 'O.' lineata. $\mathrm{V}=50 \mu \mathrm{m}$.

Fig. 8. The shape and exterior markings of the specimen in fig. 7 are typical of ' $O$.' lineata. The distal part of the endosolen was broken off during cracking. $\mathrm{V}=315 \mu \mathrm{m}$.

Figs. 9, 10. 'Oolina' squamosa (Montagu) gr.

Fig. 9. The vertical ribs which separate the columns of areolae and the endosolen are shown on this specimen which has been cracked through the apertural channel. $\mathrm{V}=145 \mu \mathrm{m}$.

Fig. 10. Detail of fig. 9 to show the root of the endosolen and the expanded part of the apertural channel (which is partly occluded with debris distal to the expansion). $\mathrm{V}=45 \mu \mathrm{m}$.

Fig. 11. Lagena sulcata (Walker \& Jacob). The smooth transition between the chamber and the neck, with no apertural apparatus at the base of the neck, differentiates this genus from the others in this study. $\mathrm{V}=75 \mu \mathrm{m}$. 

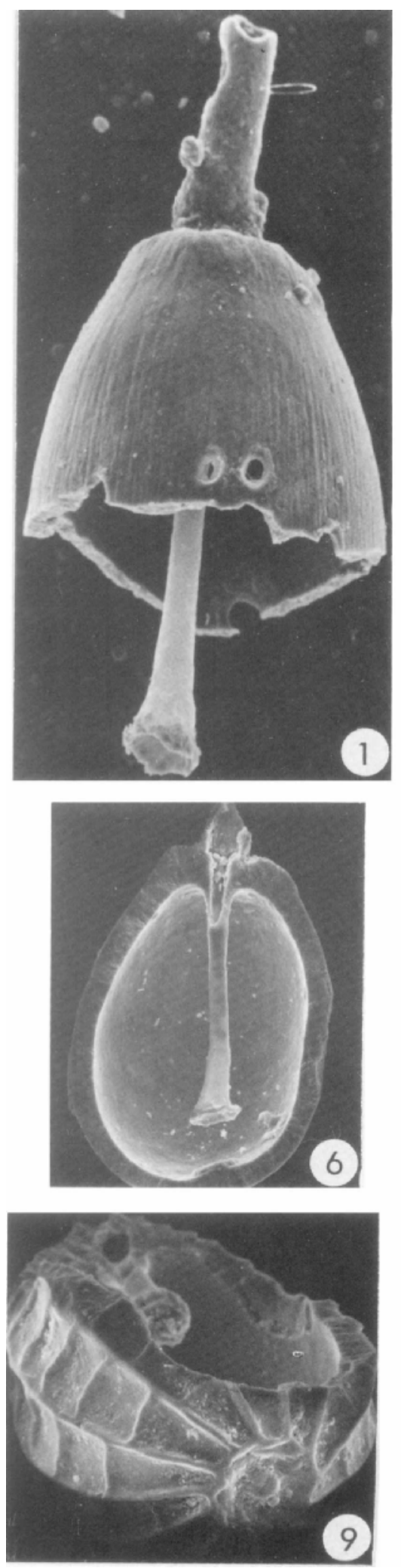
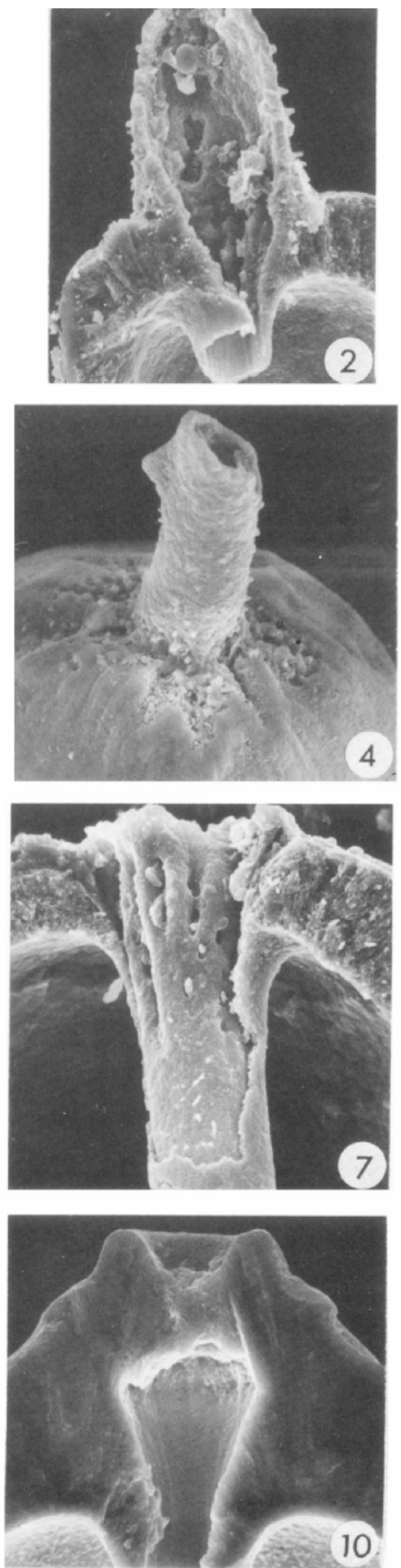
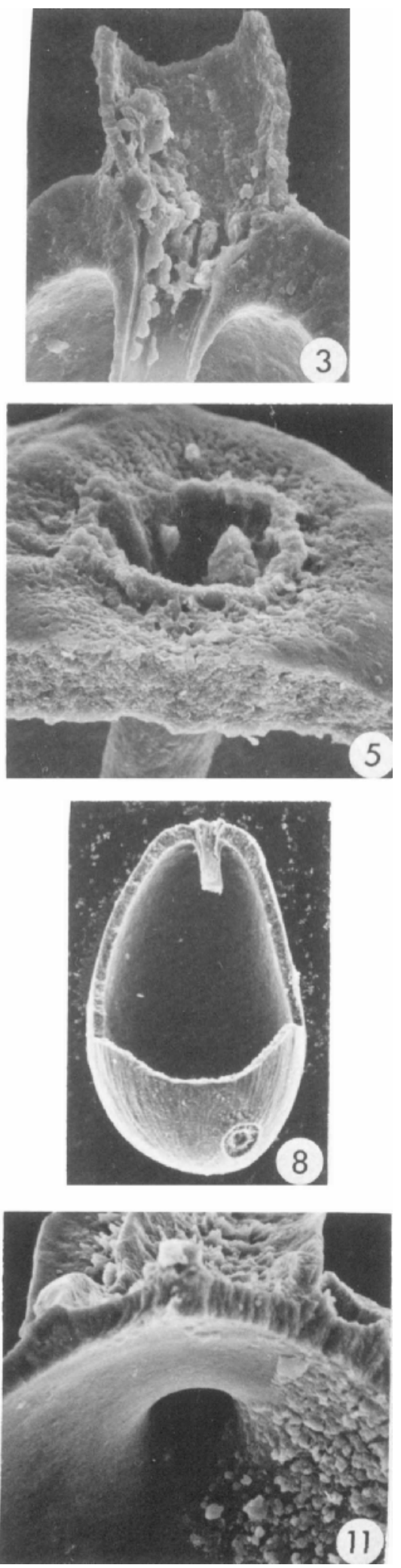
and some species presently included in Oolina as well as in certain multilocular forms (Glandulininae). This tube may have a wide range of shapes from straight to twisted; it may be split distal to the aperture and the split sides applied to the wall of the test; it may be flared or swollen distally; the free end of the tube may be split into two fine points.

Exosolen. Pl. 1, figs. 1-4, 6; Fig. 1. The external tube which is sometimes seen to cover the primary aperture of 'Oolina' lineata (Williamson, 1848) and which may be present in other species (see Parr, 1947) is called herein the apertural exosolen, while the tube sometimes present at the opposite pole of certain species is called the abapertural exosolen. If the term is used without qualification, the apertural exosolen is meant.

Endoanulus. P1. 2, figs. 1-4; Fig. 2. Some species of Oolina', for example 'O.' williamsoni (Alcock, 1865) have, in place of an endosolen, a ring which protrudes slightly into the cavity of the test. The term is introduced to describe this ring in order not to beg the question of whether this structure is homologous with the endosolen of other species. (Latin anulus, a signet ring, a diminutive of anus, so spelt with a single $n$ ).

Endodisc. Pl. 2, figs. 5-10; Fig. 4. The perforated disc present at the proximal end of the apertural channel in Anturina haynesi Jones, 1984 (= 'O.' laevigata sensu Haynes et al., 1973) and in certain multilocular species such as the polymorphinid Vasiglobulina gibba (d'Orbigny, 1826). (Note, however, that most glandulinids have an endosolen rather than an endodisc). The disc may be single or appear to consist of two similar structures of different sizes, the smaller resting on or embedded in the larger. An endodisc may have a crenate outer border.

The terms endosolen and exosolen are restricted to tubes which are distinct and structurally well-defined entities and which are not formed by a progressive narrowing of the bulbous part of a test as in the apertural region of $L$. clavata (d'Orbigny, 1846) (erroneously referred by Jones (1984) to his new genus Phialinea).

The term 'apertural apparatus' embraces those structures which are related to or comprise the opening or openings in the test. These include the apertural channel which passes through the wall of the test and leads from the lumen of the test to the outside (but excluding the lumen of an endosolen or exosolen) as well as structures, such as radial laminae, on the interal wall of the channel.

In species such as ' $O$.' williamsoni the limits of the apertural channel are precisely defined. In species in which an endosolen is present, for example 'O.' lineata, the apertural channel is continuous with the lumen of the endosolen and its proximal end is somewhat less precisely defined. In the case of $L$. clavata the proximal end of the apertural channel cannot be defined and the term should not be used for the lumen of the elongated

\section{Explanation of Plate 2}

The vertical edge of each photograph acts as a scale bar and its scale length is denoted in the captions as $\mathrm{V}$.

Figs. 1-4. 'Oolina' williamsoni (Alcock).

Fig. 1. A specimen split open through the neck to reveal the endoanulus and the long apertural channel. $V=420 \mu \mathrm{m}$.

Fig. 2. A somewhat distorted specimen showing the same features of that in fig. $1 . \mathrm{V}=400 \mu \mathrm{m}$.

Fig. 3. The endoanulus and apertural channel of a specimen cracked through the neck. $\mathrm{V}=80 \mu \mathrm{m}$.

Fig. 4. Detail of fig. 2 to show the endoanulus, the apertural channel and the constriction in this channel immediately below the aperture. $\mathrm{V}=85 \mu \mathrm{m}$.

Fig. 5. Vasiglobulina gibba (d'Orbigny). The cracked endodisc (top right) leading from the penultimate to the final chamber and the inner end of the apertural channel showing the endodisc of the aperture (lower left). $\mathrm{V}=$ $70 \mu \mathrm{m}$.

Figs. 6-11. Anturina haynesi Jones.

Figs. 6-9. The endodisc at the proximal end of the apertural channel in four specimens which show some variation in form: fig. $6, \mathrm{~V}=25 \mu \mathrm{m}$; fig. $7, \mathrm{~V}=40 \mu \mathrm{m}$; fig. $8, \mathrm{~V}=30 \mu \mathrm{m}$; fig. $9, \mathrm{~V}=25 \mu \mathrm{m}$.

Fig. 10. A specimen cracked through the aperture showing parts of the interior surfaces of three of the radial slits which lead from the proximal end of the apertural channel to the exterior. $\mathrm{V}=45 \mu \mathrm{m}$.

Fig. 11. The opening to the exterior of the radial parts of the apertural apparatus. $\mathrm{V}=80 \mu \mathrm{m}$. 

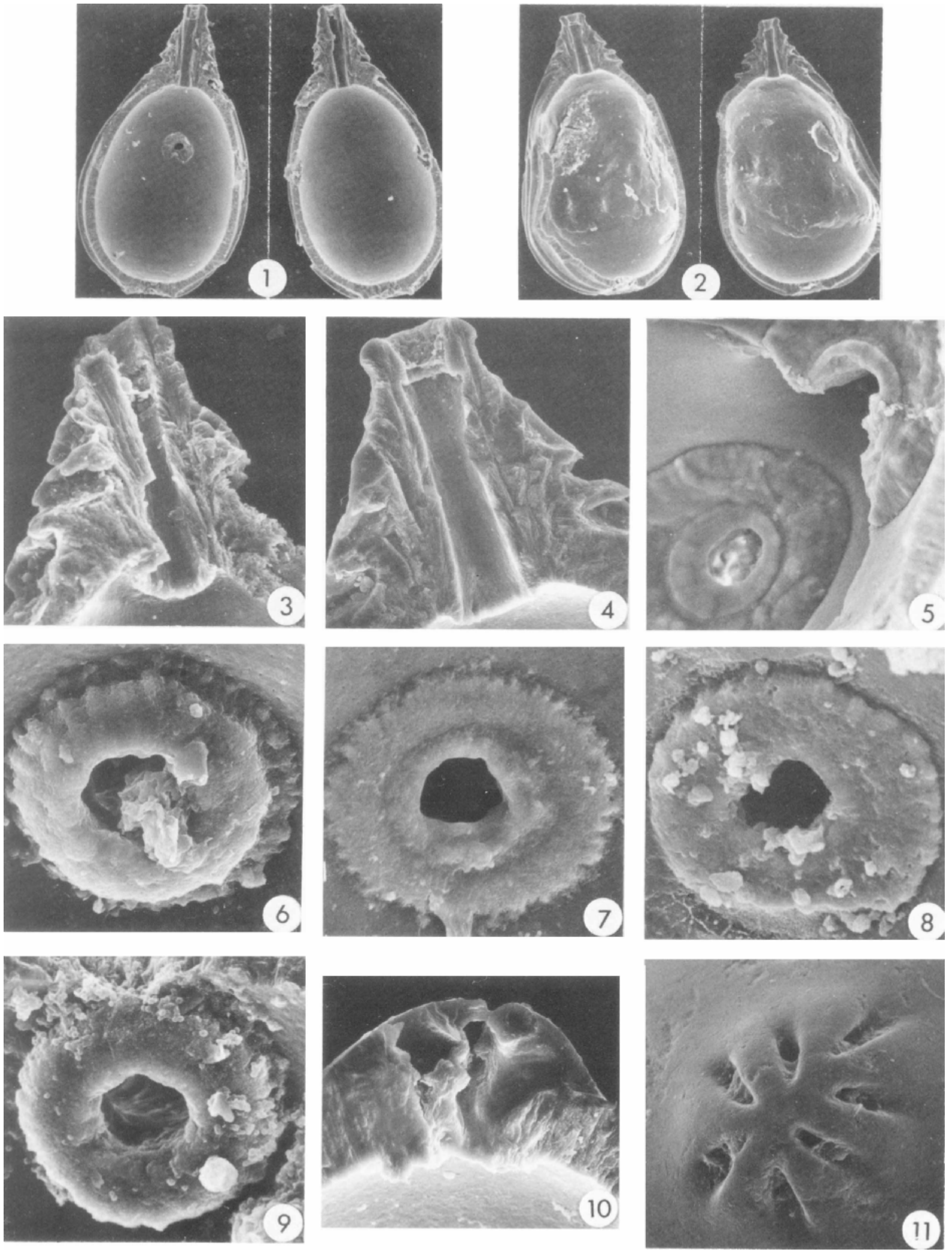
neck of this and similar species. It is, however, appropriately used in Lagenosolenia which appears to have an apertural apparatus closer to that of ' $O$.' squamosa (Montagu, 1803) than to that of L. clavata.

\section{Identification of species}

In view of the findings presented here, the four species discussed below were necessarily identified on the basis of their external appearances. In the case of 'Oolina lineata', the long endosolen, which is readily seen in the unbroken test, contributed towards the identification.

\section{Descriptions of apertural apparatuses}

S.D. = standard deviation.

'Oolina lineata' (Williamson, 1848)

Pl. 1, figs. 1-6, ?7, ?8; Fig. 1.

Dimensions (S.D.): $\mathrm{n}=120$, length 190 (32) $\mu \mathrm{m}$, width $130(16) \mu \mathrm{m}$.

The length of the endosolen is sometimes as much as three quarters the internal length of the test. Of the 120 specimens measured and the dozens more examined qualitatively, no specimen referable to this species on outward appearance alone has been seen without such an endosolen. The length of the exosolen may be half the length of the test or more but relatively few specimens have what appear to be complete exosolens so no more precise figure can be given. The apertural exosolen is typically twice the width of the endosolen and, in contrast to the latter, has an irregular shape and a rough, spiny exterior surface. It is frequently branched.

This is the most common unilocular foraminifer in the samples from Pegwell Bay and the dozens of tests examined were selected from hundreds available.

Of 120 randomly selected specimens, $14 \%$ showed by light microscopy at least a trace of an apertural exosolen and $20 \%$ showed a short abapertural exosolen.

The abapertural apparatus of this species is frequently not located at the abapertural pole of the test; in such cases the endosolen is generally directed towards the abapertural apparatus rather than the abapertural pole.

The wall of the test at the apertural end is thickened and the apertural channel, which is flared towards the exterior, passes through this thickened section. Towards the junction of the endosolen with the apertural channel, the inside of the wall of the endosolen commonly shows a number of low, narrow, longitudinally arranged ridges which continue into the apertural channel. The inner wall of the channel itself is invested with about a dozen irregular, longitudinally and radially arranged laminae between which, on the outside of the test, are the grooves which are seen to radiate from the aperture. The free edges of these laminae in the flared part of the apertural channel supports the exosolen, and the grooves are thereby turned into covered channels which end in subsidiary apertures.

In one of our specimens apparently referable to ' $O$.' lineata ( $\mathrm{Pl}, 1$, figs. 7,8$)$ the endosolen close to the aperture consists of two coaxial tubes, the outer of which is flared towards the aperture. The inner tube is fluted and holes from the fluted part lead from within the inner tube to the annular space between the two tubes. It is not known whether the coaxial tubes extended to the free end of the endosolen which is missing. Until more specimens of this form have been examined we cannot comment on the possible taxonomic, or other, significance of such an apertural apparatus. However, had the structure of the apertural apparatus not been revealed, this specimen would have been included without question in ' $O$.' lineata.

'Oolina' williamsoni (Alcock, 1865)

Pl. 2, figs. 1-4; Fig. 2.

Dimensions (S.D.): $\mathrm{n}=62$, length 266 (36) $\mu \mathrm{m}$, width $174(19) \mu \mathrm{m}$, number of ribs 17 (4.6).

The aperture is circular with no radial components. The apertural channel passes through an otherwise solid, conical part of the test of length equal to about a quarter of the total length of the test; it is truncated at the aperture. For a short distance from the aperture, the channel is somewhat constricted. The apertural channel ends on the inside of the test in an endoanulus which does not constrict the channel. The endoanulus was a constant feature of the dozens of cracked specimens examined, and no specimen has been seen in which the distance the endoanulus projects into the test approaches even half the diameter of the endoanulus. In other words, the endoanulus of this species could never be confused with the endosolen of the other species studied.

'Oolina' squamosa (Montagu, 1803) group

Pl. 1, figs. 9, 10; Fig. 3.

Dimensions (S.D.): $\mathrm{n}=24$, length $230(20) \mu \mathrm{m}$, width $158(11) \mu \mathrm{m}$, number of longitudinal ribs 14.8 (2.4).

The length of the endosolen, which is somewhat flared distally, is about one quarter of the internal length of the test. In a few specimens the endosolen broke during cracking, but in each case a careful examination revealed the broken off portion. No specimen has been examined in which the internal apparatus could have been confused with an endoanulus as defined here; an obvious endosolen is a constant feature of the dozens of cracked specimens of 'Oolina' squamosa examined.

The aperture is circular with no radial components. The apertural channel is swollen between the aperture and the root of the endosolen with a maximum width about twice that of the endosolen.

In this species, or group of species, there is very great 


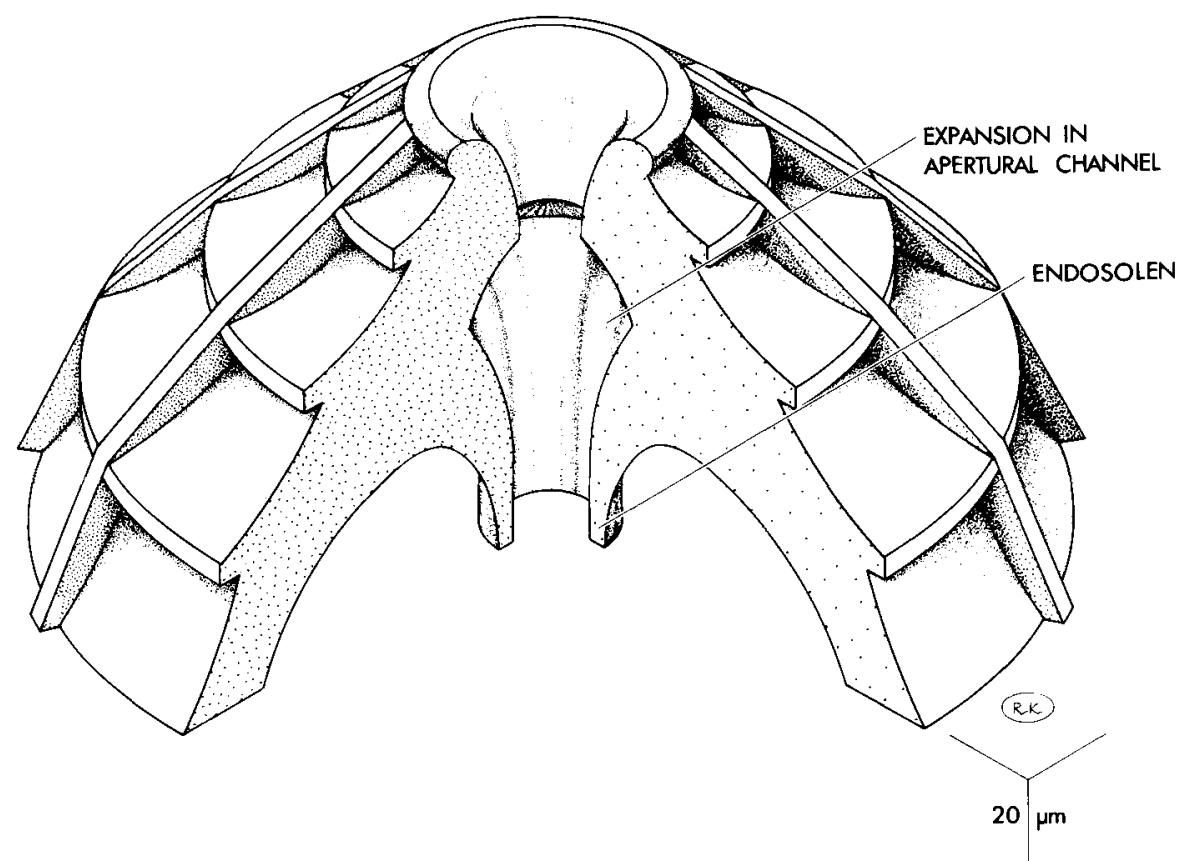

Fig. 3. 'Oolina' squamosa (Montagu) gr. Diagrammatic isometric projection of the apertural end of the test; the endosolen has been truncated.

variation in the conformation of the latitudinal boundaries of the surface areolae. In some specimens, these edges are markedly concave towards the aperture and in others straight or convex. Haynes et al. (1973) considers specimens with straight edges, referred by various authors to Oolina melo d'Orbigny, 1839, to be merely a variety of 'O.' squamosa (Montagu, 1803) which itself has concave edges and gives rise to segments with the appearance of fish scales. Haynes et $a l$. find that the scales may be irregularly arranged or be arranged in vertical rows in ' $O$.' squamosa. The hundreds of specimens examined in this study can be readily divided into those in which the vertical ribs are arranged in continuous lines from the apertural pole to the abapertural pole, and are an obvious feature, and those in which the vertical ribs are no longer than the scales, when the scales have an irregular disposition over the surface of the test. No statement concerning these differences is made here and Fig. 3 is based on the simplest geometrical forms, namely vertical ribs extending from pole to pole and latitudinal free edges of the segments of one horizontal group together making a circle.

The swelling in the apertural channel of this species was figured by Williamson (1848).

Anturina haynesi Jones, 1984

Pl. 2, figs. 6-11; Fig. 4.

Dimensions (S.D.): $\mathbf{n}=16$, length $152(19) \mu \mathrm{m}$, width 127 (12) $\mu \mathrm{m}$.
The aperture consists of up to about eight radially arranged slits which do not meet at the centre; thus no aperture opens centrally to the exterior. The slits open into an apertural channel, the inner end of which is invested with an endodisc with a crenate outer border. Such an endodisc is a constant feature of the dozens of cracked specimens which have been examined qualitatively.

\section{DISCUSSION}

In studying the apertural characteristics of ' $O$.' lineata it was necessary to consider whether the primary aperture was surrounded by a ring of subsidiary apertures or by a number of radiating grooves. It was concluded that if a difference existed between these two conditions then it was trivial and certainly of no taxonomic significance whatsoever. The situation arises because of the presence in some specimens of an apertural exosolen, in others the remains of such a tube, while in a third group there appears to be no trace of the exosolen at all. The exosolen, when present, is attached to the free edges of the radial laminae of the apertural channel. The grooves between these laminae are covered by the exosolen, and so become tubes ( $\mathrm{Pl}$. 1, fig. 3). The openings of these tubes on the upper surface of the test around the base of the exosolen then become subsidiary apertures. Thus, a specimen without any trace of an exosolen might be described as having grooves radiating from the primary aperture while one 
complete with exosolen, or even the remains of one, might be described as having a ring of subsidiary apertures surrounding the base of the exosolen.

The exosolen is very easily broken from specimens of 'O.' lineata and has been lost on a number of occasions during the manipulations leading to cracking the specimen to reveal internal structures. The presence or absence of an exosolen must not therefore be allowed to lead to variation in diagnosis in otherwise similar specimens and this point must be considered when dealing with other species such as 'O.' heronalleni Haynes et al., 1973, specimens of which may or may not have an exosolen in situ.

The abapertural exosolen of ' $O$.' lineata is never as wide nor as rough as the apertural exosolen of this species and, in spite of the freaks which were not uncommonly found in the specimens examined for this study and those described by Balkwill \& Wright (1885), it is not considered that ' $O$.' lineata is a multilocular species, moniliform or otherwise.

The introduction of the terms 'endosolen', 'endodisc' and 'endoanulus' for structures at the proximal end of the apertural channel has been made in order to differentiate clearly between these structures. The term 'exosolen' has been introduced to differentiate between the elongated neck of Lagena and the external tube of 'Oolina' lineata and 'O:' heronalleni.
Before any revision of the taxonomy of forms containing an endoanulus can be attempted, the questions must be answered whether this structure is no more than a short form of the endosolen; and, if it appears to be a structure in its own right, whether or not it should be accorded generic status as is the endosolen itself. While answers to these questions must await the second part of this study, there are certainly three, and perhaps four, markedly different types of aperture in species which have been included in 'Oolina' auct., namely those present in ' $O$.' squamosa (Montagu, 1803) group, 'O.' lineata (Williamson, 1848), Anturina haynesi Jones, 1984 , and perhaps ' $O$.' williamsoni, respectively.

In his original description of the genotype of Oolina, Oolina laevigata, d'Orbigny (1839) makes no mention of the presence of an endosolen even though one would have been visible through the transparent test wall. However, Heron-Allen \& Earland (1932) and Parr (1947) both consider that d'Orbigny's specimen has an endosolen. Without certain knowledge on this point (and on the exact nature of the rest of the apertural apparatus), certain important characteristics of the genus Oolina must remain in doubt; this is one reason why no revisions of nomenclature can presently be made.

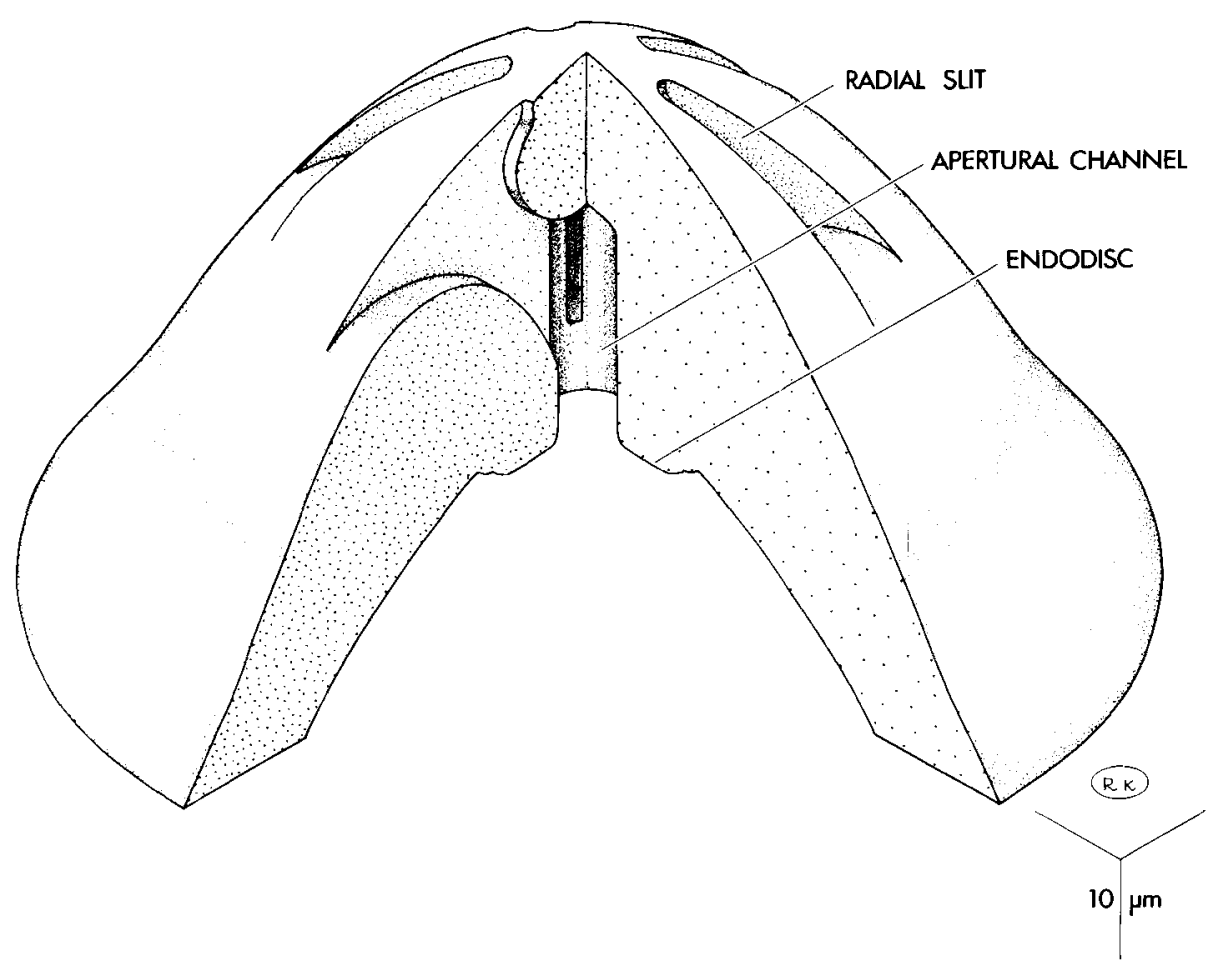

Fig. 4. Anturina haynesi Jones. Diagrammatic isometric projection of the apertural end of the test. 
Jones (1984) examined some of Williamson's specimens of Entosolenia lineata and concluded that their apertures consisted of rounded openings surrounded by radial grooves. This accords with the present findings for ' $O$.' lineata and it may, therefore, be necessary to re-establish Entosolenia for this species and ' $O$.' heronalleni, which has a similar apertural structure, in order to differentiate generically species with a simple aperture and an endosolen from those with the more complicated aperture of ' $O$ '. lineata and an endosolen. Whether or not the former type remains in Oolina depends, as stated above, on the nature of the apertural apparatus of d'Orbigny's material.

Jones (1984) described Anturina haynesi as having a 'faint trace of an entosolenian tube' (a description which would be equally appropriate for ' $O$.' williamso$n i)$. There is little doubt that his specimens are conspecific with those examined here. An emendation of his diagnosis of the subfamily Anturininae and the genus Anturina, in which reference to an entosolenian tube is replaced by reference to an endodisc, may be called for but this is not done here because of the uncertainties regarding the type specimens.

In this study we have concerned ourselves with details of the apertural apparatus in a number of species and have given no more than a passing mention to the abapertural apparatus which, in some specimens at least, is of considerable complexity. Very little is known about the function of either apparatus but it should be borne in mind that, especially when more is known about the biology of the unilocular foraminifera, the structure of the abapertural apparatus may also be found to be significant in the taxonomy of the group.

\section{CONCLUSIONS}

A detailed examination of the apertural apparatus of a number of species of unilocular foraminifera, which at some time have been included by authors in the genus Oolina, has pointed to the need for an amplification of the revision of Jones (1984) of the unilocular Nodosariida and Buliminida to take into account the different apertural types which have been found. The morphology of the apertural apparatus has been shown to be sufficient to differentiate unequivocally between the four species or species groups studied. These species belong certainly to three, and perhaps to four, genera. Whether the endoanulus in ' $O$.' williamsoni is homologous or analogous to the endosolen of other species which have been included in Oolina is not known. In the former case, ' $O$.' williamsoni may perhaps be retained in 'Oolina', the generic diagnosis of which would need to be modified to include the endoanulus as the extreme form of the endosolen. However, because of uncertainties relating to the exact nature of the apertural apparatus in Oolina d'Orbigny,
1839 and Entosolenia Williamson, 1848 (for which the type was lineata), the revision must also await a re-examination of the genoholotypes or, if these are missing, topotypes; these matters are in hand as is a study of the apertural characteristics of other species of 'Oolina'. It is, however, already clear from the present work that a detailed knowledge of the apertural apparatus must in future be a prerequisite of taxonomic work on the unilocular foraminifera.

\section{ACKNOWLEDGEMENTS}

Dr. Robert Wynn Jones has freely made available to the author his extensive knowledge of the unilocular foraminifera and his help in the preparation of this paper is gratefully acknowledged. Dr. John E. Whittaker kindly read and helpfully commented on the typescript. The work itself was made possible by the granting of facilities for the use of a Scanning Electron Microscope at Plymouth Polytechic to the author who records his grateful thanks to Prof. Malcolm Hart and $\mathrm{Mr}$. Brian Lakey for their help in respect of these facilities.

\section{Manuscript received November 1985}

Revised manuscript accepted March 1986

\section{REFERENCES}

Balkwill, F. P. \& Wright, J. 1885. Report on some Recent foraminifera found off the coast of Dublin in the Irish Sea. Trans. R. Ir. Acad., 28 (Sci), 317-372, pls. 12-14.

Haynes, J. R. et al. 1973. Cardigan Bay Recent Foraminifera. (Cruises of the R. V. Antur, 1962-1964). Bull. Br. Mus. nat. Hist. (Zool.), London, Suppl. 4, 245 pp., 33 pls.

Heron-Allen, E. \& Earland, A. 1932. Foraminifera, Part I. The ice-free area of the Falkland Islands and adjacent seas. 'Discovery' Rep., 4, 291-460, pls. 6-17.

Jones, R. W. 1984. A revised classification of the unilocular Nodosariida and Buliminida (foraminifera). Revta. Esp. Micropaleont., 16, 91-160, 8 pls.

Parr, W. J. 1947. The lagenid Foraminifera and their relationships. Proc. Roy. Soc. Victoria, 58 (N.S.) Pts. I-II, 116-129, 2 pls.

Poignant, A. 1984. La morphologie externe et interne des Oolininae - quelques aspects du tube entosolénien. Benthos '83; 2nd. Int. Symp. Benthic Foraminifera (Pau, April 1983), 501-509, 4 pl., Pau \& Bordeaux, March 1984.

Williamson, W. C. 1848. On the Recent British species of the genus Lagena. Ann. Mag. nat. Hist. ser. 2, 1, 1-20, 2 pls. 